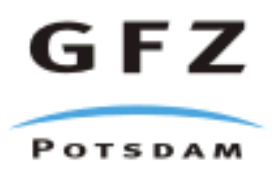

Originally published as:

Motagh, M., Hoffmann, J., Kampes, B., Baes, M., Zschau, J. (2007): Strain accumulation across the Gazikoy-Saros segment of the North Anatolian Fault inferred from Persistent Scatterer Interferometry and GPS measurements. - Earth and Planetary Science Letters, 255, 3-4, 432-444

DOI: 10.1016/j.epsl.2007.01.003. 


\title{
Strain accumulation across the Gazikoy-Saros segment of the North Anatolian Fault inferred from Persistent Scatterer Interferometry and GPS measurements
}

\author{
Mahdi Motagh $^{\text {a,* }}$, Jörn Hoffmann ${ }^{\text {b }}$, Bert Kampes ${ }^{c}$, Marzieh Baes ${ }^{\text {d }}$, Jochen Zschau ${ }^{\text {a }}$ \\ ${ }^{a}$ GeoForschungsZentrum Potsdam (GFZ), Haus E (Sektion 2.1), Telegrafenberg, D-14473 Potsdam, Germany \\ ${ }^{\mathrm{b}}$ German Aerospace Center (DLR), German Remote Sensing Data Center (DFD), Oberpfaffenhofen 82234 Wessling, Germany \\ ${ }^{\mathrm{c}}$ German Aerospace Center (DLR), Remote Sensing Technology Institute (IMF), Oberpfaffenhofen 82234 Wessling, Germany \\ ${ }^{\mathrm{d}}$ Faculty of Earth Sciences, Utrecht University, Budapestlaan 4, 3584 CD Utrecht, The Netherlands
}

Received 28 December 2005; received in revised form 13 July 2006; accepted 1 January 2007

Editor: R.D. van der Hilst

\begin{abstract}
We use a combination of Persistent Scatterer Interferometry (PSI) and GPS observations to study interseismic crustal deformation on the Gazikoy-Saros segment (Ganos fault) of the North Anatolian Fault (NAF) zone, northwestern Turkey. The data include 44 C-band radar images collected by the ERS1 and ERS2 satellites in descending orbits between 1992 and 2003 over the study area, and campaign GPS horizontal velocities from 7 stations. The resultant secular velocity field is inverted using a nonlinear minimization algorithm to estimate parameters of two interseismic deformation models: aseismic deep slip in a purely elastic earth model (elastic half-space rheology), and viscoelastic flow in an elastic-viscoelastic earth model (viscoelastic-coupling rheology). The following conclusions are drawn: (1) The fault locking depth is estimated in the range of $\sim 8-17 \mathrm{~km}(95 \%$ confidence interval) regardless of the rheological model. (2) The elastic half-space model implies an upper bound of 20-27 mm/yr for the slip rate on the Ganos fault. (3) Models incorporating viscoelastic rheology and seismic cycle effects suggest a lower slip rate of $18-24 \mathrm{~mm} / \mathrm{yr}$, which agrees more closely with geological estimates. However, these values are slightly sensitive to the assumed earthquake recurrence interval. (4) A bootstrap analysis of deformation data yields average crust-upper mantle viscosities of $1.3 \times 10^{19}-3.6 \times 10^{20} \mathrm{~Pa}$ s for the Ganos area.
\end{abstract}

(C) 2007 Elsevier B.V. All rights reserved.

Keywords: Persistent Scatterer Interferometry; elastic half-space; viscoelastic half-space; inversion; Ganos fault

\section{Introduction}

The North Anatolian Fault (NAF), with a total length of about $1500 \mathrm{~km}$, is one of the most active dextral (right-lateral) strike-slip faults in the world. It defines

\footnotetext{
* Corresponding author. Tel.: +49 3312881299.

E-mail address: motagh@gfz-potsdam.de (M. Motagh).
}

the tectonic boundary between the Anatolian Plate and the Eurasian Plate in northern Turkey, accommodating $\sim 14-30 \mathrm{~mm} / \mathrm{yr}$ of relative plate motion between the two plates [1-5]. The Gazikoy-Saros segment (the Ganos fault) is the onshore segment of the northern strand of the NAF between the Marmara Sea and the Gulf of Saros (Fig. 1). It was last ruptured in 1912 with a $\mathrm{Ms}=7.4$ earthquake that broke the entire inland segment 


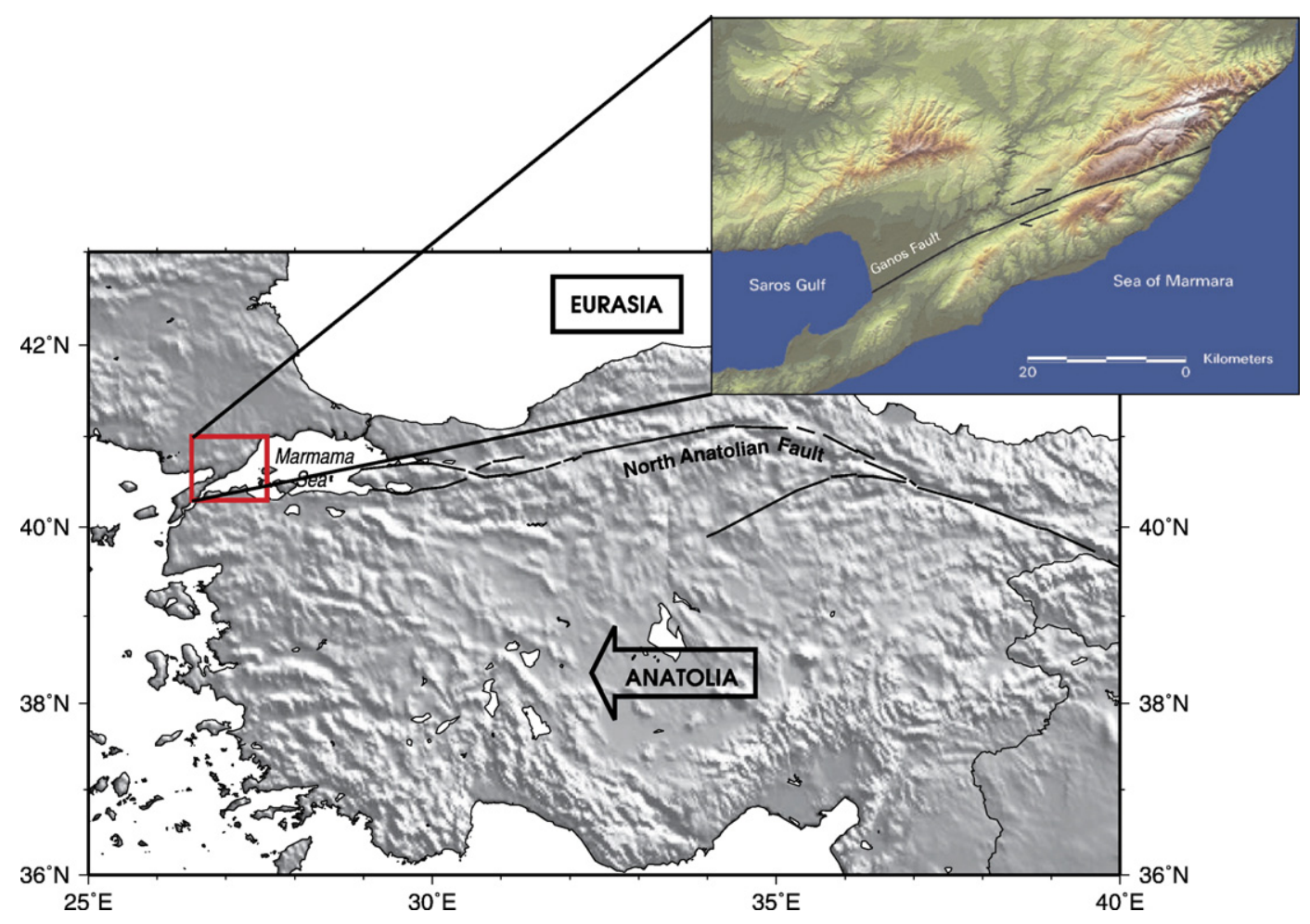

Fig. 1. Simplified map of Turkey. The inset illustrates the shaded-relief topographic map of the study area. The Ganos fault, the onshore segment of northern strand of the North Anatolian Fault between the Sea of Marmara and the Gulf of Saros, is indicated by a thick line.

of the fault, a length of about $50 \mathrm{~km}$, and produced a right-lateral strike-slip component of at least $3 \mathrm{~m}$. Other large historical earthquakes that have been attributed to the Ganos fault occurred in A.D. 824, 1343, 1509 and 1766 [5].

Interseismic geodetic observations around active fault zones can be used to place important constraints on kinematic and dynamic models of earthquake processes $[6,7]$. This requires that geodetic networks be sufficiently dense to allow for accurate estimation of fault model parameters. Differential radar interferometry (DINSAR) has the potential to measure small deformation signals accurately over wide areas with fine spatial resolution [8]. However, in areas with vegetation and steep topography, characterizing most of the western end of the NAF, the use of InSAR is hindered by large amounts of temporal decorrelation. Furthermore, atmospheric signals can affect interferometric measurements. They are difficult to differentiate from small deformation signals over large areas in particular. Consequently, atmospheric signals can hamper efforts to detect small-scale interseismic deformation in areas such as the Ganos fault using conventional interferometric techniques.

In this study we have applied the Persistent Scatterer Interferometry (PSI) technique [9-11], using data from the European Space Agency satellites, ERS1 and ERS2, to map interseismic line-of-sight (LOS) velocities across the Ganos fault. Morphotectonic features and seismological data show strong evidence for dextral (rightlateral) motion in this region [5]. However, the GPS coverage there is very sparse [2,3]. Thus, we use interferometric measurements to get a more complete picture of interseismic crustal deformation.

\section{Observations}

The radar data that we use in this study include all available ERS1 and ERS2 images (Track 150; frame: 2781) acquired from a descending orbit over the Ganos fault during the time period 1992-2003 (see Table 1). These data are processed using the PSI-GENESIS interferometry software developed at the German Aerospace Center (DLR) [11]. Five ERS2 acquisitions (orbits: $30,565,31,567,34,072,35,074$ and 40,585) are excluded from the processing because of their large (more than $1000 \mathrm{~Hz}$ ) Doppler centroid frequency difference. Consequently, 38 differential interferograms are generated with a common master scene acquired from orbit 24687 (ERS2: 04-April-1996). Fig. 2 shows 12 examples of differential interferograms which were produced 
Table 1

Available ERS frames over the Ganos fault

\begin{tabular}{|c|c|c|c|}
\hline Orbit & Date & $\begin{array}{l}b_{\text {perp }} \\
(\mathrm{m})\end{array}$ & Satellite \\
\hline 4804 & 16-Jun-1992 & $\sim 54$ & E1 \\
\hline 5806 & 25-Aug-1992 & $\sim 229$ & E1 \\
\hline 6307 & 29-Sep-1992 & $\sim 404$ & E1 \\
\hline 6808 & 03-Nov-1992 & $\sim 996$ & E1 \\
\hline 7309 & 08-Dec-1992 & $\sim 335$ & E1 \\
\hline 7810 & 12-Jan-1993 & $\sim 68$ & E1 \\
\hline 8812 & 23-Mar-1993 & $\sim 381$ & E1 \\
\hline 9313 & 27-Apr-1993 & $\sim 1021$ & E1 \\
\hline 10,315 & 06-Jul-1993 & $\sim-760$ & E1 \\
\hline 12,319 & 23-Nov-1993 & $\sim 918$ & E1 \\
\hline 19,677 & 20-Apr-1995 & $\sim 20$ & E1 \\
\hline 20,178 & 25-May-1995 & $\sim-32$ & E1 \\
\hline 20,679 & 29-Jun-1995 & $\sim-874$ & E1 \\
\hline 21,180 & 03-Aug-1995 & $\sim 454$ & E1 \\
\hline 2008 & 08-Sep-1995 & $\sim-1045$ & E2 \\
\hline 2509 & 13-Oct-1995 & $\sim 1184$ & E2 \\
\hline 24,186 & 29-Feb-1996 & $\sim 757$ & E1 \\
\hline 24,687 & 04-Apr-1996 & o & E1 \\
\hline 6016 & 14-Jun-1996 & $\sim-347$ & E2 \\
\hline 7018 & 23-Aug-1996 & $\sim-659$ & E2 \\
\hline 7519 & 27-Sep-1996 & $\sim-68$ & E2 \\
\hline 8020 & 01-Nov-1996 & $\sim 1243$ & E2 \\
\hline 16,036 & 15-Мay-1998 & $\sim 697$ & E2 \\
\hline 17,038 & 24-Jul-1998 & $\sim-243$ & E2 \\
\hline 18,040 & 02-Oct-1998 & $\sim 812$ & E2 \\
\hline 19,042 & 11-Dec-1998 & $\sim-963$ & E2 \\
\hline 21,046 & 30-Apr-1999 & $\sim-200$ & E2 \\
\hline 22,549 & 13-Aug-1999 & $\sim 1289$ & E2 \\
\hline 23,050 & 17-Sep-1999 & $\sim-61$ & E2 \\
\hline 23,551 & 22-Oct-1999 & $\sim-88$ & E2 \\
\hline 24,052 & 26-Nov-1999 & $\sim 111$ & E2 \\
\hline 24,553 & 31-Dec-1999 & $\sim 589$ & E2 \\
\hline 25,555 & 10-Mar-2000 & $\sim-14$ & E2 \\
\hline 26,557 & 19-May-2000 & $\sim 420$ & E2 \\
\hline 27,058 & 23-Jun-2000 & $\sim-732$ & E2 \\
\hline 27,559 & 28-Jul-2000 & $\sim-328$ & E2 \\
\hline 28,561 & 06-Oct-2000 & $\sim 85$ & E2 \\
\hline 29,062 & 10-Nov-2000 & $\sim 400$ & E2 \\
\hline 29,563 & 15-Dec-2000 & $\sim 580$ & E2 \\
\hline 30,565 & 23-Feb-2001 & $\sim 2910$ & E2 \\
\hline 31,567 & 04-May-2001 & $\sim 3051$ & E2 \\
\hline 34,072 & 26-Oct-2001 & -36 & E2 \\
\hline 35,074 & 04-Jan-2002 & $\sim-487$ & E2 \\
\hline 40,585 & 24-Jan-2003 & $\sim-370$ & E2 \\
\hline
\end{tabular}

Data are sorted based on acquisition time. Perpendicular baseline is with respect to the master orbit 24,687 .

from SAR images in Table 1 and corrected for topography using a 3 arc-second ( $\sim 90 \mathrm{~m})$ SRTM digital elevation model [12]. Not surprisingly, almost all interferograms are dominated by large amounts of decorrelation noise. This arises from the vegetation ground cover and steep topography across this part of the NAF. Of the 38 interferograms constructed here, only one pair (19677-24687) seems to contain some gentle phase gradients across the region. Assuming there is no contribution due to residual topography and orbital errors, the interferometric phase in this pair is composed mainly of two components: a small interseismic signal, accumulated over 11 months, and a presumably shortterm noise due to atmosphere [13]. As suggested in previous studies $[14,15]$, one way to isolate interseismic crustal deformation signal from the atmospheric noise is to combine ('stack') multiple interferograms, constructed from all possible combinations of SAR images. Our attempts to do so, however, failed to produce good results due to poor coherence that occurs at the $\mathrm{C}$-band wavelength $(\sim 5.6 \mathrm{~cm})$ of the ERS in this area (results not shown here). Therefore, in the following, we focused our data processing strategy on the persistent scatterer technique.

Fig. 3 shows the overall structure for the Persistent Scatterer Interferometry (PSI) processing used in this study. The persistent scatterers are extracted from calibrated amplitude SAR images using the Signal-toClutter Ratio (SCR) technique [16]. Pixels whose average signal to clutter ratio is above a certain threshold in all SAR acquisitions are considered to be less affected by temporal and/or geometrical decorrelation, and selected as potential persistent scatterers. This technique works on the principle that the phase error $\sigma_{\phi}$ of a point scatterer can be related to its SCR by [16]:

$\sigma_{\phi}=\frac{1}{\sqrt{2 \mathrm{SCR}}}$

Therefore, pixels with high SCR are expected to possess a stable phase behavior that can be analyzed further in a multi-interferogram framework to yield information about relative motion over time or other parameters of interest. The signal power is estimated at the considered pixel while the clutter power is estimated from the surrounding pixels. Estimation of the SCR is done using the average intensity image [16]. Here, we set the threshold at $\mathrm{SCR}=5$ to ensure that errors caused by temporal decorrelation and/or atmospheric artifacts remain negligible. This threshold is much higher than what is typically used in urban areas. It was chosen higher to select only pixels that most surely had a low phase noise, because the distance between pixels was large (up to $5 \mathrm{~km}$ ), which implies that unmodeled phase due to atmospheric difference signal could be large. Next, we derive an initial phase model for the DEM error and linear displacement rate between PSs using the integer least-squares estimator with an a priori stochastic model for interferometric phase observations at point scatterers $[17,18]$. The wrapped residual phase at PS 


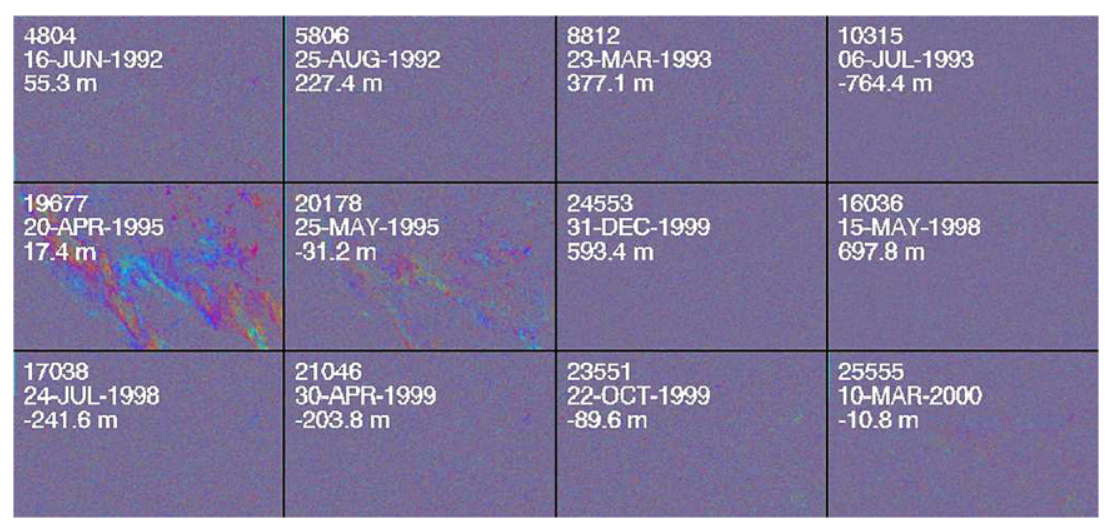

Fig. 2. Some differential interferograms for the Ganos area, track 150. The master image was acquired on April 4th, 1996. The interferograms are corrected for topography using a 3 arc-second $(\sim 90 \mathrm{~m})$ SRTM digital elevation model, and sorted from left to right according to temporal baseline.

points is then computed by subtracting the initial phase model from the original (wrapped) differential interferometric observations. This residual phase per interferogram, assumed to be composed of a low-frequency part due to atmosphere and a relatively small amplitude, high frequency part due to random noise, is unwrapped using the sparse grid MCF algorithm [19], after which the total unwrapped field at point scatterers is obtained by addition of the unwrapped residual phase to the initial model. The final estimates for the DEM error, linear displacement rate, and average atmospheric delay are made simultaneously by the weighted least-squares method using unwrapped data at PS points (For more detail, refer to [18]).

Fig. 4a shows linear displacement rates observed at persistent scatterers across the Ganos fault between 1992 and 2000. The velocities are superimposed on the average amplitude SAR image and are with respect to a reference point on the fault labeled by a black asterisk.
The measurements are in the radar line-of-sight (LOS) reference, with red indicating $-5 \mathrm{~mm} / \mathrm{yr}$ (LOS) motion away from the satellite and blue indicating $5 \mathrm{~mm} / \mathrm{yr}$ (LOS) motion toward the satellite.

The general pattern for the velocity field shown in Fig. 4a is consistent with our expectation of tectonic deformation due to right-lateral shear on the Ganos fault. We observe an overall positive range-change rate on the north side of the fault, assumed to be caused by horizontal motion toward the satellite, and negative range-change rate on the south side of the fault, assumed to be caused by horizontal motion away from the satellite. However, some localized inhomogeneities in the velocity field are also seen across the region that could be caused by non-tectonic deformations or unaccounted errors in the SAR data.

Fig. $4 \mathrm{~b}$ displays a posteriori variance factors for the estimated LOS velocities at persistent scatterers across

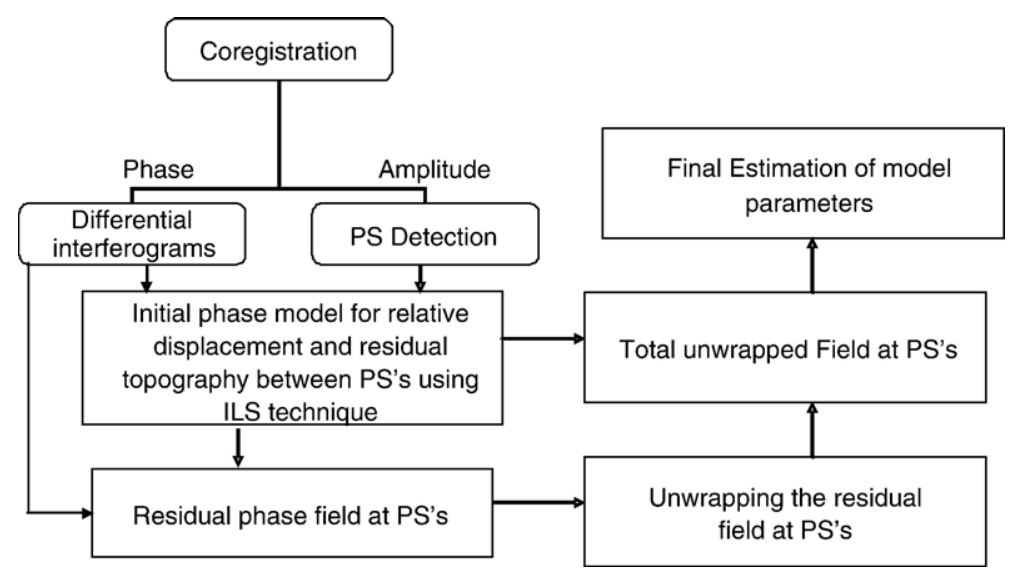

Fig. 3. Flow-chart of the Persistent Scatterer Interferometry technique [11], developed at the German Aerospace Center (DLR). 
(a)

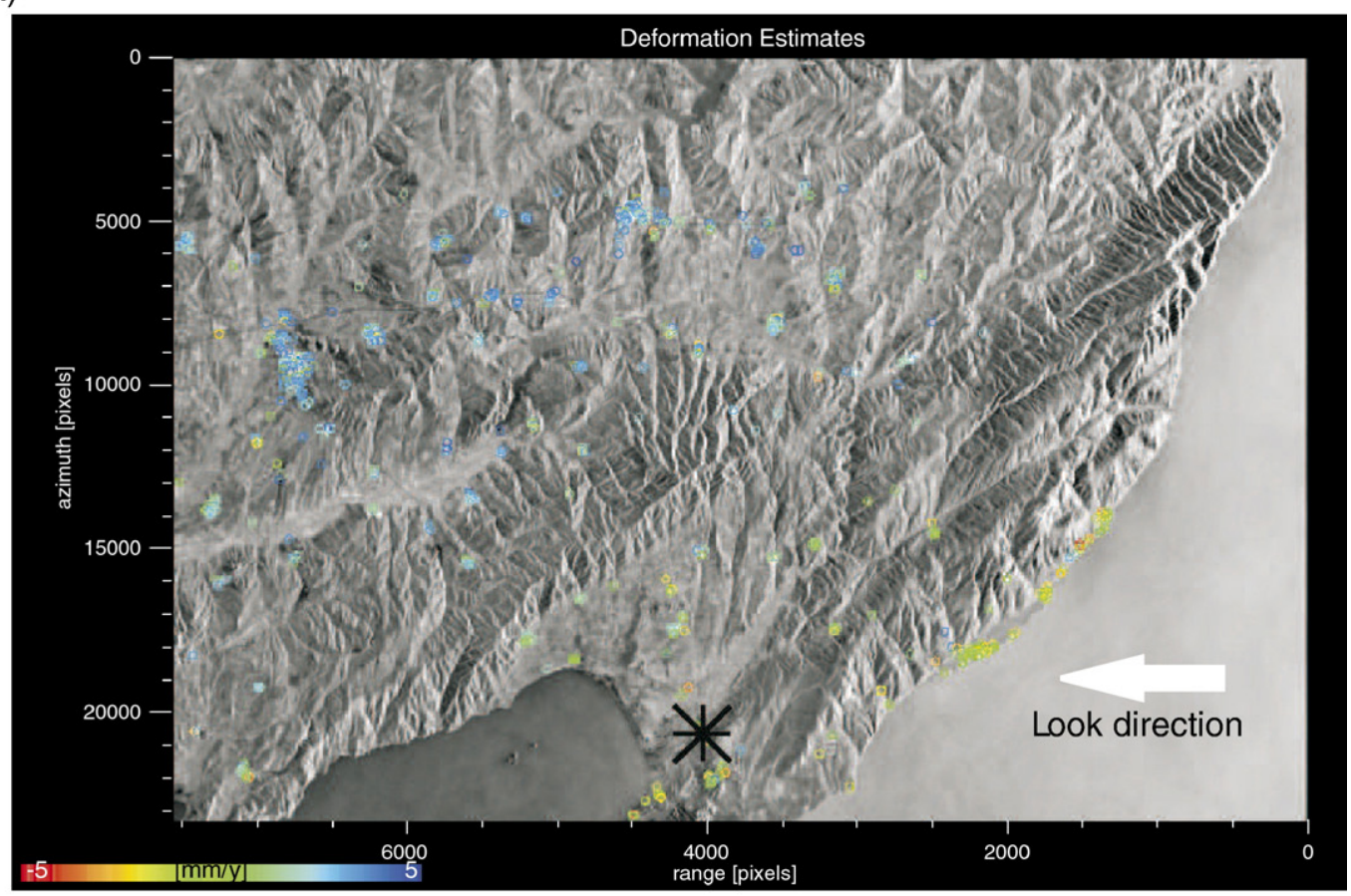

(b)

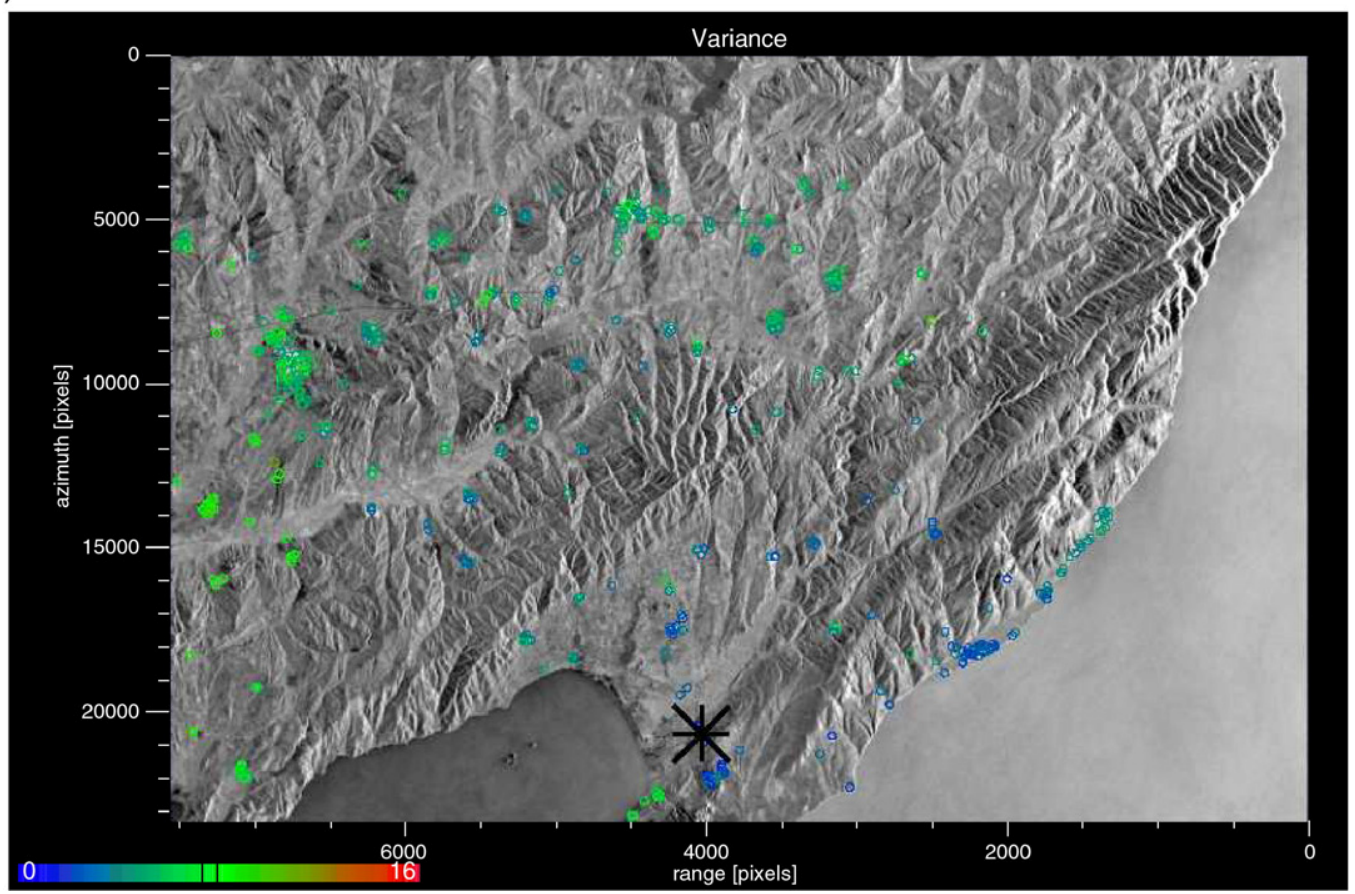

Fig. 4. (a) Estimated line-of-sight (LOS) displacement rates at permanent scatterers across the Ganos fault between 1992 and 2000 . The velocities are superimposed on the average amplitude SAR image and are with respect to a reference point on the fault marked with an asterisk. Red corresponds to $-5 \mathrm{~mm} / \mathrm{yr}$ (LOS) motion away from the satellite and blue to $5 \mathrm{~mm} / \mathrm{yr}$ (LOS) motion toward the satellite (b) A posteriori variance factors (relative to the reference point), estimated using unwrapped data at PS points. A factor of $\sigma^{2}=1$ corresponds to a standard deviation of about $\pm 0.2 \mathrm{~mm} / \mathrm{yr} ; 16$ indicates variance becomes 16 times more, i.e. a standard deviation of about $4 *( \pm 0.2)= \pm 0.8 \mathrm{~mm} / \mathrm{yr}$. 
the Ganos fault. These values describe the precision of PS velocities relative to the reference point, and are computed based on the unwrapped least-squares phase residuals by [18]:

$\sigma^{2}=\frac{e^{T} Q^{-1} e}{r}$

where $e$ is the unwrapped residual phase vector, $Q$ is the variance-covariance matrix of double-difference phase observations, and $\mathrm{r}$ is the redundancy (the number of interferograms minus the number of estimated parameters). A factor of $\sigma^{2}=1$ in Fig. $4 \mathrm{~b}$ corresponds to a standard deviation of about $\pm 0.2 \mathrm{~mm} / \mathrm{yr} ; 16$ indicates variance becomes 16 times more, i.e. a standard deviation of about $4 *( \pm 0.2)= \pm 0.8 \mathrm{~mm} / \mathrm{yr}$. In general, the precision of estimated velocities deteriorates with distance from the reference point, which is due to the atmospheric difference signal, which is expected to increase with distance from the reference point. The variance factors for some PS points around the Saros Golf, however, are larger than the average value estimated for neighboring points with approximately the same distances to the reference point. We suspect that the linear velocity model used in the PSI processing does not fully describe the deformation field at these locations, resulting in the presence of unmodeled displacement signal in the residuals and large variance factors.

The detected ground motion in Fig. 4a is a projection of 3D surface deformation vectors (East, North, Up) on to the look direction of the satellite. However, without a priori information line-of-sight observations from a single geometry can not resolve 3 components of deformation from each other. Because the ERS satellite looks at the surface at a relatively steep angle, which is $23^{\circ}$ off-vertical in the center of a SAR frame and perpendicular to the orbital track, line-of-sight measurements are least sensitive to North-South deformations. They are also approximately 2.4 times more sensitive to vertical deformations than to East-West deformations. Although there is geologic evidence for dip-slip component of motion along the Ganos fault [20], seismotectonic and GPS-based geodetic studies suggest that the strikeslip component is dominant [1-5]. Therefore, we consider range-change rates shown in Fig. $4 \mathrm{a}$ as reflecting mostly right-lateral shear deformation across the Ganos fault.

A quantitative assessment of the spatial distribution of the PS velocities is made by constructing a velocity transect perpendicular to the average strike of the Ganos fault in the area. Assuming purely dextral horizontal motion, fault-parallel velocities $v_{f}$ are obtained from lineof-sight velocities $v_{\text {los }}$ by [15]:

$v_{f}=\frac{v_{\text {los }}}{\sin \Theta_{\text {inc }}(\cos \alpha \sin \phi-\sin \alpha \cos \phi)}$

Here $\Theta_{\text {inc }} \sim 23^{\circ}$ is the average incidence angle of the ERS, $\phi \sim 63^{\circ}$ is the average strike of the Ganos fault, and $\alpha \sim 190^{\circ}$ is the heading of the satellite orbit for descending ERS tracks. Fig. 5a shows the resulting profile of the velocity distribution from 1992 to 2000 , constructed from the PS observations. The results reveal a pattern for the velocity distribution that is representative (typically first-order) of the process of interseismic strain accumulation along strike-slip faults. We observe over a centimeter of fault-parallel motion across the entire region, with the highest gradient near the trace of the fault that decays slowly with distance away from the fault. The scattering of projected PS data along the profile is due to several reasons, including displacement gradient parallel to the strike of the fault, local

(a)

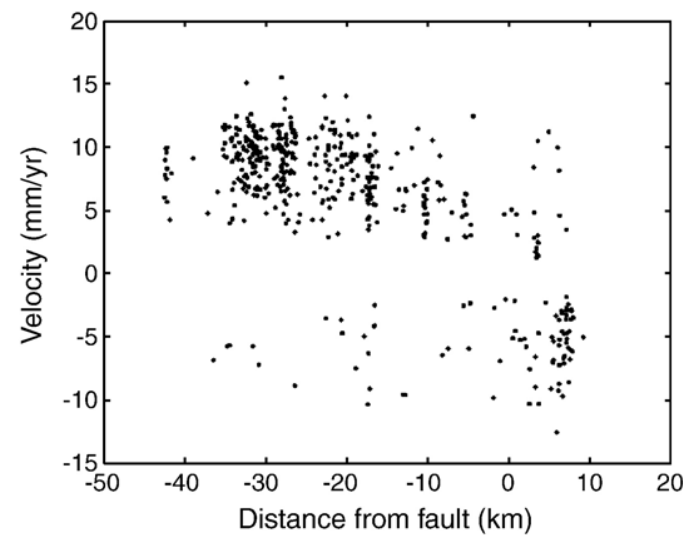

(b)

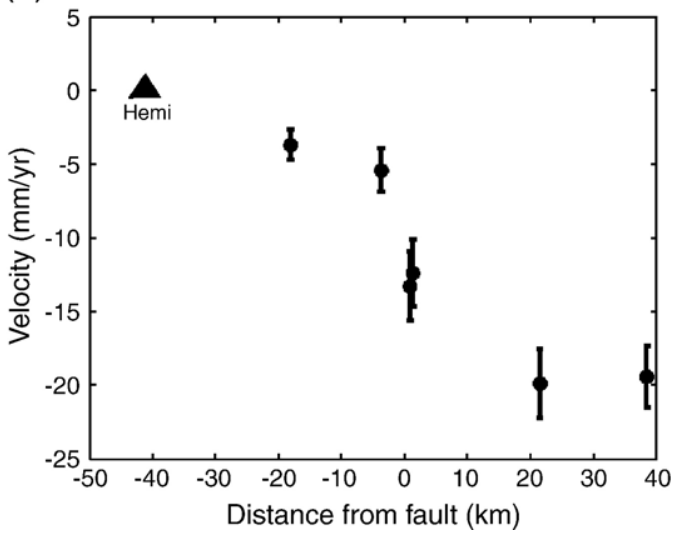

Fig. 5. (a) Projection of PS velocities onto profile perpendicular to the strike of the Ganos fault. (b) GPS measurements of fault-parallel deformation relative to the reference point Hemi [3]. 
displacements of non-tectonic origin, or errors in the data. PS points which deviate from the dense part of the profile are due to local deformations or wrong estimates, and are excluded from the modeling using statistical methods (next section). In the following we invert the PS data in Fig. 5a, together with horizontal measurements from 7 GPS sites in the region (Fig. 5b), to constrain parameters of interseismic deformation models at the Ganos fault. The GPS velocities are obtained from Straub et al. [3], and are relative to the station Hemi marked with a triangle in Fig. 5b.

\section{Data analysis}

We use the observed deformation at the Ganos fault (PS plus GPS data) to examine two different models of

(a)

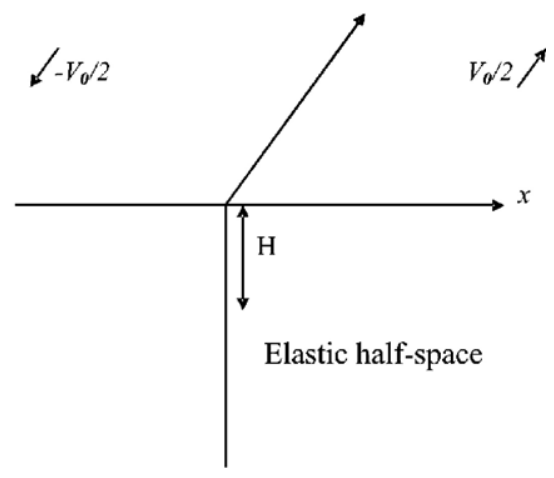

(b)

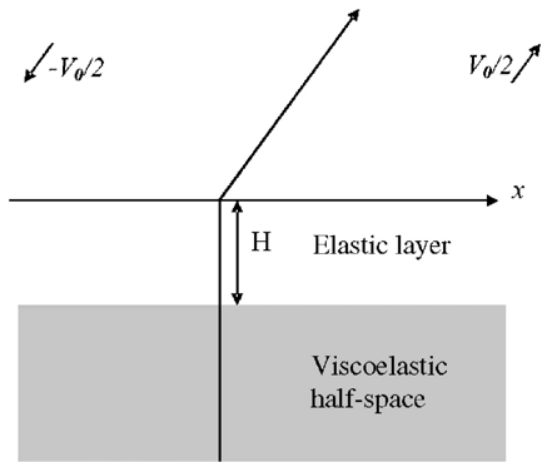

Fig. 6. Earth models employed to describe interseismic deformation for an infinitely, long, vertical strike-slip fault. (a) An elastic halfspace rheology. The fault is locked from the surface to depth, $H$, but slips freely below that depth at a rate equal to the secular relative plate motion $v_{0}$. (b) Viscoelastic-coupling rheology with an elastic layer (lithosphere) of thickness $H$ overlying a Maxwell-type viscoelastic half-space (asthenosphere). The fault penetrates all of the lithosphere but does not continue into the asthenosphere. Each earthquake causes instantaneous stress changes in the underlying half-space which will then relax over time via viscoelastic flow at depth. the earthquake deformation cycle associated with strike-slip faults. The first, and most widely used, model is that of Savage and Burford [21] in which the process of strain accumulation and release along transform faults is described by a buried screw dislocation in an elastic half-space (Fig. 6a). No slip takes place on the upper portion of the fault between earthquakes, but the lower part creeps continously at a constant rate. For an infinitely long, planar, vertical fault which is locked down to a depth $H$ but slips freely below that depth, the fault-parallel velocity as a function of position perpendicular to the fault $x$ is:

$v(x)=\left(v_{0} / \pi\right) \tan ^{-1}(x / H)$

where $v_{0}$ is the slip rate on the fault.

The second model, the so-called viscoelastic coupling model, incorporates the effect of viscoelastic flow at depth into the spatial and temporal patterns of crustal deformation around transform faults. The assumed earth model consists of an elastic layer (lithosphere/schizosphere) of thickness $H$, overlying a Maxwell viscoelastic half-space (asthenosphere/plastosphere). The fault penetrates all of the lithosphere but does not continue into the asthenosphere (Fig. 6b). Each coseismic slip event in the lithosphere causes instantaneous stress changes in the underlying half-space which will then relax over time via viscoelastic flow at depth. The interseismic deformation is obtained by superposing time dependent deformations resulting from an infinite sequence of earthquakes that periodically rupture the entire lithosphere [22]. For a long, vertical, strike-slip fault the velocity field in this model as a function of distance across strike, $x$, and time since the last earthquake, $t$, is given by [7]:

$v(x, t)=\left(v_{0} / \pi\right) \sum_{n=1}^{\infty} \phi\left(t / \tau_{R}, T / \tau_{R}\right) F_{n}(x, H)$

where

$$
\phi\left(t / \tau_{R}, T / \tau_{R}\right)=\frac{T}{\tau_{R}} \frac{e^{-t / \tau_{R}}}{(n-1) !} \sum_{k=0}^{\infty} e^{-k T / \tau_{R}}\left(\frac{t+k T}{\tau_{R}}\right)^{n-1}
$$

and

$F_{n}(x, H)=\tan ^{-1}\left[\frac{2 x H}{x^{2}+(2 n H)^{2}-H^{2}}\right]$

Here $v_{0}$ is the far-field lithospheric velocity, $\tau_{R}$ is the relaxation time of the Maxwell material $\left(\tau_{R}=2 \eta / \mu\right.$, where $\eta$ is the viscosity and $\mu$ is the shear modulus, 
taken to be equal to that of the elastic plate), and $T$ is the interval between periodic slip events.

Note that both the elastic and viscoelastic models provide very idealized descriptions of Earth's rheology and the corresponding mechanism of crustal deformation at transform faults. They make no provision for the dip-slip component of motion on strike-slip faults, nor do they account for material heterogeneities. Neither considers displacement gradient parallel to the fault or asymmetry in the strain pattern across the fault. The viscoelastic-coupling model has an advantage over the elastic half-space model in that it accounts for timedependent deformations in the earthquake cycle. It also represents a somewhat more realistic picture of Earth's rheology than does the elastic half-space model. Nonetheless, despite all inherent limitations and oversimplifications, both models have been successfully employed in crustal deformation studies and have proven to work quite well at least for reproducing many of the first order features of observed deformation at transform boundaries [e.g., 23-25].

The viscoelastic coupling model is specified by five parameters: lithospheric thickness/locking depth $H$, relaxation time $\tau_{R}$, recurrence time interval $T$, time since the last earthquake $t$, and far-field velocity $v_{0}$. The elastic half-space model, on the other hand, depends only on two variables: locking depth $H$ and slip rate $v_{0}$. In order to estimate these parameters, we perform a nonlinear inversion using the PS and GPS data through minimization of the mean square misfit:

$\mathrm{MSE}=\frac{1}{n-p} \sum_{i=1}^{n}\left(\frac{y_{i}-g\left(x_{i}, P\right)}{\sigma_{i}}\right)^{2}$

where $P$ is the model parameter vector with length $p, n$ is the number of data, $y$ is the data vector, $g$ is the model prediction at a given point $x_{i}$, and $\sigma_{i}$ is the standard deviation of observation point $y_{i}$. The errors for horizontal GPS velocities are taken from [3]. The a posteriori precision for PS velocities is computed based on the unwrapped least-squares phase residuals using Eq. (2). The nonlinear inversion is followed by a standard procedure for outlier detection using out-of-context test at $95 \%$ confidence interval [26], to identify and reject those observations which are statistically incompatible with the rest of observational data. As discussed above, for the PSI observations this incompatibility may arise from a number of factors, including displacement gradient parallel to the fault, wrong estimates, or any local deformation other than the dominant interseismic signal.

It has to be pointed out that the quadratic form used in Eq. (2) to derive the precision of PS points does not account for the statistical dependence (covariance) between observations. This might bias least-squares estimates of model parameters and their associated confidence intervals in the inverse problem [26,27]. We address this issue by carefully interpreting small misfits in the search space of parameters, and constructing bootstrap confidence intervals as detailed below.

To estimate confidence intervals for the model parameters, we perform a residual bootstrap analysis [27] as follows: Let $\Sigma=L L^{T}$ denote the Cholesky decomposition of the data covariance matrix. The weighted residuals of the best fitting model, $\hat{\varepsilon}=L^{-1}\left(d^{\text {obs }}-d^{\text {cal }}\right)$, is randomly sampled with replacement as $\varepsilon^{*}$, and added to the predicted data according to $d^{*}=d^{\text {cal }}+L \varepsilon^{*}$. This vector is then used in the nonlinear inversion to generate a new model estimate. The resampling and estimation steps are repeated many times, yielding an ensemble of solutions the distribution of which is an estimate of the uncertainty.

\section{Results}

For the nonlinear inversion, we use a LevenbergMarquadt nonlinear optimization algorithm [28] with a priori bounds on parameters as listed in Table 2. The two parameters $H$ (locking depth/elastic thickness) and $v_{0}$ (slip rate/far-field velocity), common for both aforementioned interseismic models, are bound to lie within a range of 5-30 km and $14-30 \mathrm{~mm} / \mathrm{yr}$, respectively. The lower bound of $5 \mathrm{~km}$ for the lithospheric thickness comes from GPS-based estimate of the locking depth in the Northern Sea of Marmara [29]. The lower and upper bound for the slip rate are taken from the published slip rates for the NAF [1]. The a priori bound on the relaxation time $\tau_{R}$ is set to be broad, $1-10^{4} \mathrm{yr}$, corresponding to viscosity values of $10^{18}$ to $10^{22} \mathrm{~Pa} \mathrm{~s}$. The time since the last large earthquake on the Ganos fault (1912) is known and, therefore, considered fixed in the viscoelastic-coupling model $(t=93)$. The recurrence time is constrained to 275 and $340 \mathrm{yr}$ based on the average return period found by Rockwell et al. [30] using trenching and historical data.

The best fitting elastic half-space model is found for $H \sim 12 \mathrm{~km}$ and $v_{0} \sim 23 \mathrm{~mm} / \mathrm{yr}$. Fig. 7a-b show the result

Table 2

A Priori bounds on parameters

\begin{tabular}{lcl}
\hline Parameter & Min & Max \\
\hline Lithospheric thickness/locking depth $(H), \mathrm{km}$ & 5 & 30 \\
Far-field velocity/Slip rate $\left(v_{0}\right), \mathrm{mm} / \mathrm{yr}$ & 14 & 30 \\
Relaxation time, yr & 1 & $10^{4}$ \\
\hline
\end{tabular}


(a)

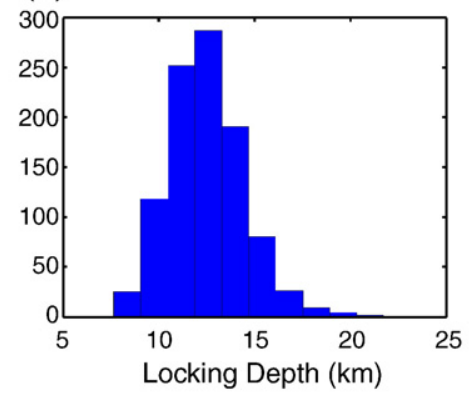

(b)

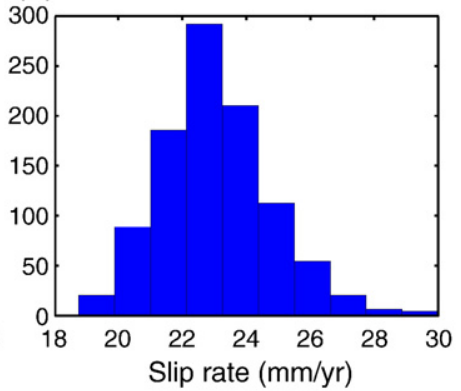

(c)

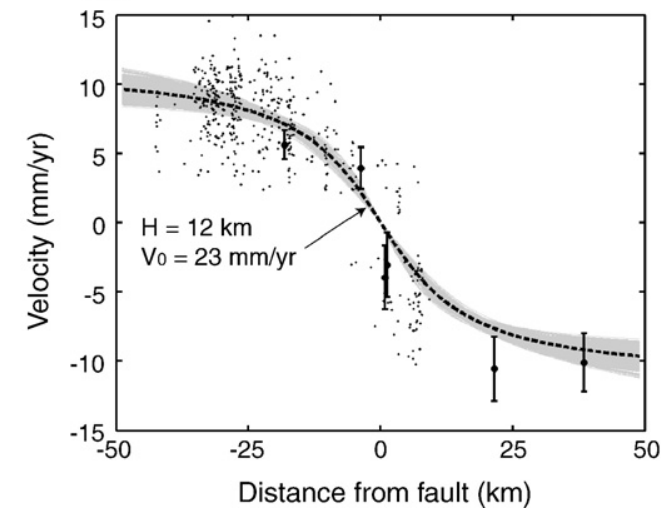

Fig. 7. (a,b) Probability distribution for the locking depth and slip rate from bootstrap results using PS and GPS data. (c) Fit to deformation data using elastic half-space model for the range of parameters determined from the bootstrap method. The best fit model is represented by a dashed line.

of 1000 models from the bootstrap analysis as described in Section 3. Both parameters in the elastic model are resolved well within a priori bounds set in the inversion.
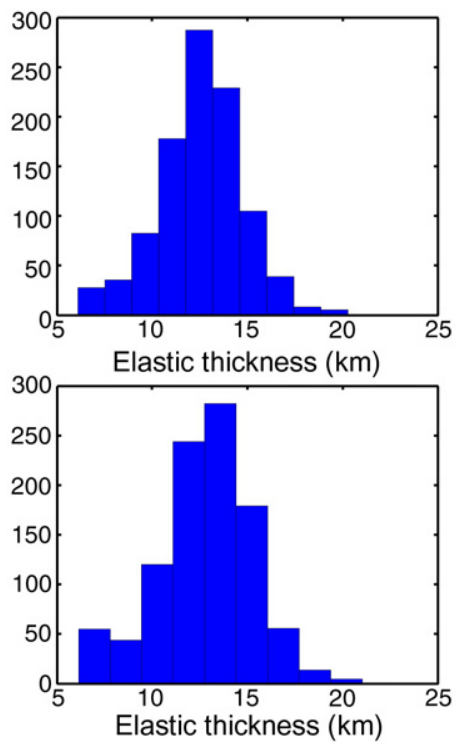
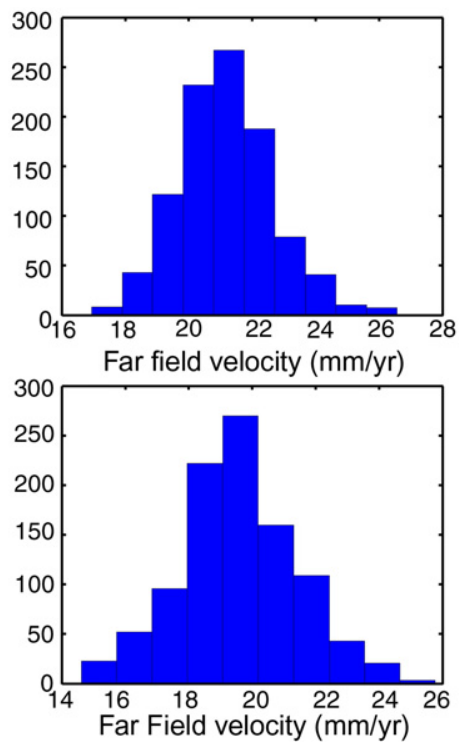

We find that at the $95 \%$ confidence interval slip rate of $20-27 \mathrm{~mm} / \mathrm{yr}$ and locking depth of $9-17 \mathrm{~km}$ are consistent with geodetic observations. Fig. 7c illustrates
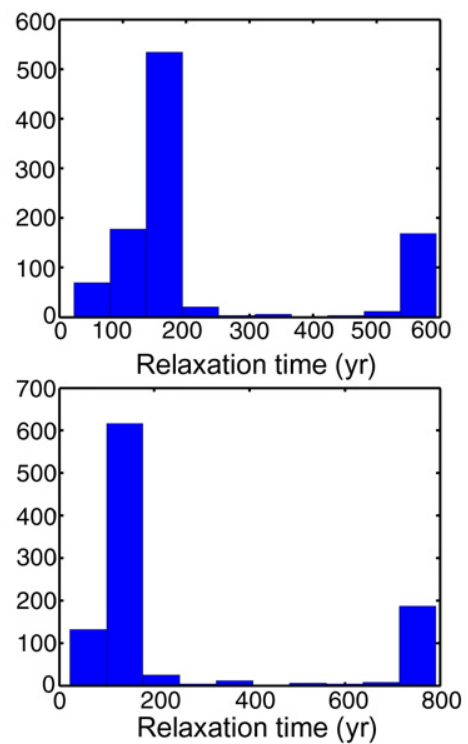

Fig. 8. Probability distribution for parameters of the viscoelastic-coupling model from bootstrap results using PS and GPS data. The upper panel corresponds to the recurrence interval of $T=275 \mathrm{y}$ and the lower panel to $T=340 \mathrm{y}$. 
the fit between the data and the forward models for the range of locking depths and slip rates determined above. The best fit model is represented by a dashed line.

For the viscoelastic-coupling model with the characteristic recurrence time of $275 \mathrm{yr}$, the optimum solution is $H \sim 13 \mathrm{~km}, \tau_{R} \sim 142 \mathrm{yr}$, with the slip rate of $v_{0}$ $\sim 21 \mathrm{~mm} / \mathrm{yr}$. Increasing the recurrence interval to $340 \mathrm{yr}$ does not affect the estimate for the locking depth $(H$ $\sim 13 \mathrm{~km}$ as before), but slip rate and relaxation time decrease to $19 \mathrm{~mm} / \mathrm{yr}$ and $123 \mathrm{yr}$, respectively. Fig. 8 shows the results of 1000 models from bootstrap samples of residuals; the upper panel corresponds to $T=275 \mathrm{y}$ and the lower panel to $T=340 \mathrm{y}$. The elastic thickness is resolved within $9 \mathrm{~km}(8-17 \mathrm{~km})$ in both test models. A $275 \mathrm{yr}$ recurrence interval on the Ganos fault results in a slip rate of $18-24 \mathrm{~mm} / \mathrm{yr}$ and a relaxation time of $28-600 \mathrm{yr}$, while a $340 \mathrm{yr}$ recurrence interval

(a)

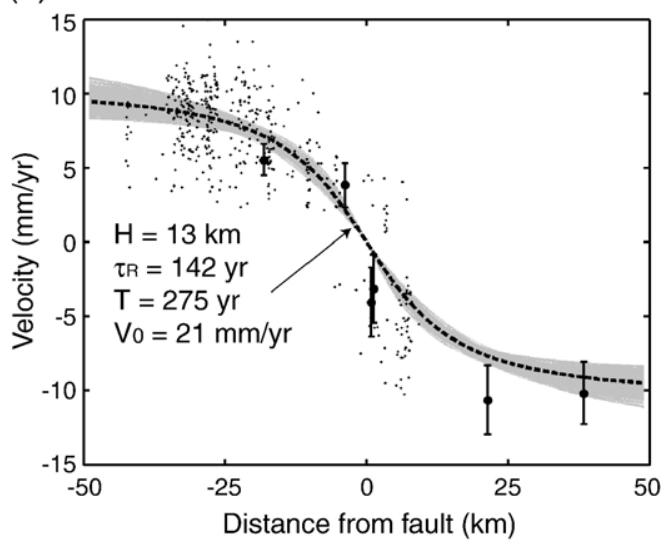

(b)

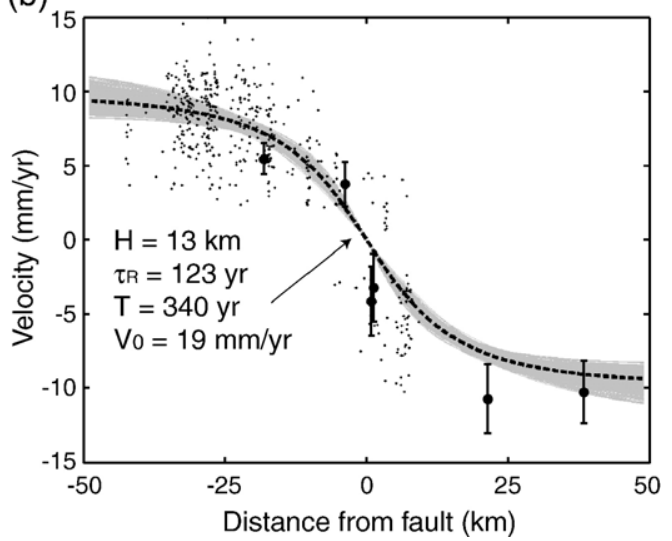

Fig. 9. Fit to deformation data using viscoelastic-coupling model for the range of parameters determined from the bootstrap method. (a) Forward models with the 275-year recurrence interval. (b) Same as (a) with the 340-year recurrence interval. The dashed line in both figures represents the best fit model that has the smallest misfit to the data. results in a slip rate of $16-23 \mathrm{~mm} / \mathrm{yr}$ and a relaxation time of $27-800$ yr. Fig. 9 illustrates the fit between the data and the forward models for the range of model parameters determined above; the dashed line represents the best fit model that has the smallest misfit to the data.

\section{Discussion}

The interseismic deformation pattern that we inferred over 8 yr from PSI observations across the Ganos fault provide valuable constraints on the kinematics of deformation at the fault. The inversion of surface velocity data in both elastic and viscoelastic half-space rheologies suggests a locking depth in the range of $\sim 8-$ $17 \mathrm{~km}$. This is consistent with the maximum depth of coseismic rupture obtained for the two most recent large events (the 1999 Izmit and Düzce earthquakes) along the NAF zone $[31,32]$, and the regional locking depth of $\sim 12-17 \mathrm{~km}$ in land regions surrounding Marmara inferred from GPS and seismic studies [29,33,34].

Using an elastic half-space model, we estimate an upper bound of $23 \pm 4 \mathrm{~mm} / \mathrm{yr}$ for the slip rate on the Ganos fault, assuming that all the relative motion between two plates is accommodated only on one fault trace. This agrees well with previous geodetic-based upper bound estimates: $30 \pm 2 \mathrm{~mm} / \mathrm{yr}$ [4], $22 \pm 3 \mathrm{~mm} / \mathrm{yr}$ [3], $24 \pm 1 \mathrm{~mm} / \mathrm{yr}$ [2], $21 \mathrm{~mm} / \mathrm{yr}$ [35], and $24.8 \pm 1.6 \mathrm{~mm} / \mathrm{yr}$ [29]. It is also in relatively good accord with the average geological rate of $16-25 \mathrm{~mm} / \mathrm{yr}[1,5,36]$. However, models incorporating viscoelastic rheology and seismic cycle effects predict slip rates that are in better agreement with geological estimates. For example, a viscoelasticcoupling model that uses a recurrence time of $275 \mathrm{yr}-$ the best estimate of the average interval obtained from dated trench sections and historical data [30] -predicts a slip rate in the range of $18-24 \mathrm{~mm} / \mathrm{yr}$. The assumed value for the recurrence time can affect these estimates slightly, but for the tested range of intervals the predictions of viscoelastic coupling models fall well within the range specified by geological observations. This serves to emphasize the importance of incorporating a more realistic Earth rheology when interpreting interseismic crustal deformation data near active fault zones $[7,24,25]$.

While the a posteriori distribution of the slip rate and locking depth approximately follows a normal distribution in the viscoelastic model (Fig. 8), the a posteriori distribution for the relaxation time appears bimodal, with two prominent peaks near $\sim 165$ and $560 \mathrm{yr}$ for a recurrence time of $T=275 \mathrm{y}$ (upper panel) and near $\sim 137$ and $750 \mathrm{yr}$ for a recurrence time of $T=340 \mathrm{y}$ (lower panel), although the secondary peaks in both diagrams have much lower probability. Compared to the 
slip rate and locking depth, the relaxation time is less well constrained in the inversion. We note that in the inversion of geodetic data we have not used any prior information on the relaxation time. Nevertheless, the latter is well resolved within bounds assumed in the inversion (1$\left.10^{4} \mathrm{yr}\right)$. The bimodal distribution in Fig. 8 could be caused by a number of factors, including the nonlinearity of the viscoelastic solution in Eqs. (5)-(7), the relatively large scattering of PS data in Fig. 5a, and complexities arising from the strong trade-off between parameters (e.g. between the locking depth and the relaxation time, as well as between the locking depth and slip rate). The most probable peaks of 165 and $137 \mathrm{yr}$ are less than the average earthquake recurrence interval of the Ganos fault ( 275-340 a), indicating that viscoelasticity might affect considerably surface velocity distribution during the earthquake cycle [22,7]. The less probable peaks of 560 and $750 \mathrm{yr}$, on the other hand, are far greater than the recurrence interval, suggesting that surface velocity distribution might be fairly steady with time and that elastic half-space rheology might successfully fit earthquake-cycle deformation data [22,7]. Our inversion results appear to favor viscous behavior over the elastic one, because the former has much higher probability. Robust prior information from seismology and geology on the locking depth and Holocene slip rate would increase our ability to better resolve the relaxation time and the average viscosity of the asthenosphere on the basis of surface deformation data $[37,38,39]$.

The two-layer viscoelastic structure that we used in this paper treats the lower crust and upper mantle as a single unit whose rheology is represented by a Maxwell body. As one can see in Fig. 8, for reasonable values of the earthquake recurrence interval the deformation data yields asthenosphere relaxation time of $\sim 28-780 \mathrm{yr}$, which corresponds to a viscosity of $\sim 1.3 \times 10^{19}-3.6 \times$ $10^{20} \mathrm{~Pa} \mathrm{~s}$, if we assume the average crust-upper mantle shear modulus of $30 \mathrm{Gpa}$. Our lower bound for the viscosity is at least two orders of magnitude greater than what has been inferred for the post-1999 Izmit transient deformation east of the Marmara sea as measured by continuous and campaign GPS surveys [40]. A likely explanation for this discrepancy in the viscosity estimate is the effect of nonlinear rheology [41]; that is, the viscosity is low early in the earthquake cycle when stresses are large, but is high later in the cycle when stresses become dissipated. However, the possibilities for other explanations such as the existence of a completely different thermomechanical structure in the west and east of the Marmara Sea or aseismic creep below the seismogenic part of the lithosphere can not be ruled out $[38,39,42]$.
The elastic half-space and the Maxwell viscoelastic coupling models are the simplest of rheological models to describe interseismic deformation near a strike-slip fault. They have been widely employed to study faultzone deformation using geodetic data [e.g., 14,15,21$25,43]$. Until recently there were very few, if any, detailed earthquake-cycle observations to help distinguish between these simple models and more complicated ones. However, recent developments in spacebased geodesy, in particular InSAR and GPS, have provided many opportunities to collect detailed observations of the space-time history of crustal deformation over a wide range of space and time scales. This together with revolutionary advances in computational power in recent years has generated considerable interest for more advanced modeling to gain a better understanding of the rheology of the subsurface and the mechanics of crustal deformation. A small but growing collection of studies now argue for transient or even nonlinear rheology to describe fault-zone deformation data [41,44-48].

However, for several reasons we consider the simple Maxwell or half-space rheology adequate to address interseismic deformation in this study. First, other complicated models such as non-Maxwellian or power-law non-linear rheology might be very important to explain the spatial and temporal evolution of surface deformation immediately after an earthquake, as well documented, for example, for the 1992 Landers and the 1999 Hector Mine earthquakes [45,46,48], the June 2000 earthquakes in Iceland [47], and the 2002 Denali earthquake [44]. However, given the time interval between our observations and the last event on the Ganos fault ( $\sim 93$ y) and the estimated earthquake recurrence interval $(\sim 275-340$ a), it is highly unlikely that steady state has not yet been reached and that transient or non-linear rheology plays a significant role on surface velocity distribution. Second, utilizing more complicated rheologies will add more parameters into the Earth model, of which many are not known or poorly constrained. Third, complexities of transient and powerlow rheology would result in a myriad of trade-offs between different model parameters which can not be reliably resolved using the inversion of only surface deformation data. Finally, the limited number of persistent scatterers and GPS observations used in this study together with intrinsic uncertainties arising from scattering of the PSI data and infrequent GPS measurements, justifies the use of Maxwell and half-space rheology instead of more complicated models.

There are certain limitations to our observations and interpretations. Our measure of misfit $\sqrt{\mathrm{MSE}}$ (see Eq. (8)), which accounts for the number of observations and 
parameters, is greater than 1 for both elastic half-space and viscoelastic coupling models. PS points which are influenced by severe atmospheric artifacts and/or hydrological and surface processes are the main cause for large misfit. These unmodeled signals together with deformation components arising from the effects of elastic heterogeneity, anisotropy and three dimensional fault geometry are not accounted for by the two-dimensional tectonic models in Section 3, resulting in an MSE for best-fitting models which is high. Nevertheless, despite these limitations the observed interseismic deformation data at the Ganos fault are able to resolve parameters of considerable interest such as slip rate, locking depth and viscosity which can be used to refine models of crustal deformation and provide a greater understanding of earthquake hazard for the western Marmara region.

\section{Conclusion}

We have applied the Persistent Scatterer Interferometry technique to map tectonic/interseismic deformation from 1992 to 2000 at the Gazikoy-Saros segment (Ganos fault) of the North Anatolian Fault (NAF) zone, northwestern Turkey. The analysis of PS data, together with observations from 7 GPS stations in the region, provides valuable constraints on the mechanisms governing the deformation at the fault. The inversion of geodetic data using elastic half-space rheology indicates right-lateral slip at 20 $27 \mathrm{~mm} / \mathrm{yr}$ (95\% confidence interval) on a vertical fault below 9-17 km depth. Models that account for the viscoelastic rheology and seismic cycle effects do not change significantly our estimates for the fault locking depth $(\sim 8-17 \mathrm{~km})$, but predict a lower right-lateral slip rate of $18-24 \mathrm{~mm} / \mathrm{yr}$. The assumed earthquake recurrence interval in viscoelastic models can affect slightly slip rate estimates, but for reasonable values of the recurrence time slip rates are lower and in better agreement with geological data in viscoelastic models than in elastic half-space models. A bootstrap analysis of deformation data at the Ganos fault indicates average crust-upper mantle viscosities of $1.3 \times 10^{19}-3.6 \times 10^{20} \mathrm{~Pa}$ s. The resolution of parameters investigated in this study depends strongly on the precision and temporal and spatial density of deformation measurements, as well as on the prior information provided by seismological and geological studies.

\section{Acknowledgments}

SAR data was provided by ESA through Category-1 project 2892. Many thanks go to Sandra Richwalski for reading the manuscript and giving constructive com- ments. We thank Roland Bürgmann, Stephan Sobolev, Frank Roth, Yuri Fialko and Nico Adam for valuable discussions and greatly appreciate constructive review comments by an anonymous reviewer.

\section{References}

[1] A. Barka, The North Anatolian Fault zone, Ann. Tecton. 6 (1992) 164-195.

[2] S. McClusky, et al., GPS constraints on plate motions and deformations in eastern Mediterranean and Caucasus, J. Geophys. Res. 105 (2000) 5695-5719.

[3] C. Straub, H.G. Kahle, C. Schindler, GPS and geologic estimates of the tectonic activity in the Marmara Sea region, NW Anatolia, J. Geophys. Res. 102 (1997) 27,587-27,601.

[4] R.E. Reilinger, S.C. McClusky, M.B. Oral, R.W. King, M.N. Toksoz, A.A. Barka, I. Kinik, O. Lenk, I. Sanli, Global Positioning System measurements of present-day crustal movements in the Arabia-Africa-Eurasia plate collision zone, J. Geophys. Res. 102 (1997) 9983-9999.

[5] N.N. Ambraseys, C. Finkel, The Saros-Marmara earthquake of 9 August 1912, Earthquake Eng. Struct. Dyn. 15 (1987) 189-211.

[6] J.C. Savage, M. Lisowski, Viscoelastic coupling model of the San Andreas fault along the big bend, southern California, J. Geophys. Res. 103 (1998) 7281-7292.

[7] P. Segall, Integrating geologic and geodetic estimates of slip rate on the San Andreas fault system, Int. Geol. Rev. 44 (2002) $62-82$.

[8] A.K. Gabriel, R.M. Goldstein, H.A. Zebker, Mapping small elevation changes over large areas: differential radar interferometry, J. Geophys. Res. 94 (1989) 9183-9191.

[9] A. Ferretti, C. Prati, F. Rocca, Permanent scatterers in SAR interferometry, IEEE Trans. Geosci. Remote Sens. 39 (2001) $8-20$.

[10] A. Hooper, H. Zebker, P. Segall, B. Kampes, A new method for measuring deformation on volcanoes and other natural terrains using InSAR persistent scatterers, Geophys. Res. Lett. 31 (2004), doi:10.1029/2004GL021737.

[11] N. Adam, B. Kampes, M. Eineder, J. Worawattanamateekul, M. Kircher, The development of a scientific permanent scatterer system. ISPRS Workshop High Resolution Mapping from Space, Hannover, 2003, pp. 1-6, cdrom.

[12] http://seamless.usgs.gov/website/seamless/products/srtm3arc. asp.

[13] R. Bürgmann, P. Rosen, E.J. Fielding, Synthetic aperture radar interferometry to measure Earth's surface topography and its deformation, Annu. Rev. Earth Planet. Sci. 28 (2000) 169-209.

[14] T.J. Wright, B.E. Parsons, E.J. Fielding, Measurement of interseismic strain accumulation across the North Anatolian Fault by satellite radar interferometry, Geophys. Res. Lett. 28 (2001) 2117-2120.

[15] S. Lyons, D. Sandwell, Fault creep along the southern San Andreas from InSAR, permanent scatterers, and stacking, J. Geophys. Res. 108 (2003), doi:10.1029/2002JB001831.

[16] N. Adam, B.M. Kampes, M. Eineder, The development of a scientific persistent scatterer system: Modifications for mixed ERS/ENVISAT time series, ENVISAT/ERS Symposium, Salzburg, 2004, pp. 1-9, cdrom.

[17] B.M. Kampes, R.F. Hanssen, Ambiguity resolution for permanent scatterer interferometry, IEEE Trans. Geosci. Remote Sens. 42 (2004) 2446-2453. 
[18] B.M. Kampes, Radra Interferometry : Persistent Scatterer Technique, Springer, ISBN-10:140204576X, 2006.

[19] M. Einder, J. Holzner, Phase unwrapping of low coherence differential interferograms, International Geoscience and Remote Sensing Symposium, Hamburg, 28 June-2 July, 1999, pp. 1-4, cdrom.

[20] L. Seeber, O. Emre, M.H. Cormier, C.C. Sorlien, C.M.G. McHugh, A. Polonia, N. Ozer, N. Cagatay, Uplift and subsidence from the oblique slip: The Ganos-Marmara bend of the north Anatolian transform, Western Turkey, Tectonophysics 391 (2004) 239-258.

[21] J.C. Savage, R.O. Burford, Geodetic determination of relative plate motion in central California, J. Geophys. Res. 78 (1973) 832-845.

[22] J.C. Savage, W.H. Prescott, Asthenosphere readjustment and the earthquake cycle, J. Geophys. Res. 83 (1978) 3369-3376.

[23] W.H. Prescott, J.C. Savage, J.L. Svarc, D. Manaker, Deformation across the Pacific-North America plate boundary near San Francisco, California, J. Geophys. Res. 106 (2001) 6673-6682.

[24] T.H. Dixon, E. Norabuena, L. Hotaling, Paleoseismology and Global Positioning System: Earthquake-cycle effects and geodetic versus geologic fault slip rates in the Eastern California shear zone, Geology 31 (2003) 55-58.

[25] T.H. Dixon, J. Decaix, F. Farina, K. Furlong, R. Malservisi, R. Bennett, F. Suarez-Vidal, J. Fletcher, J. Lee, Seismic cycle and rheological effects on estimation of present-day slip rates for the Agua Blanca and San Miguel-Vallecitos faults, northern Baja California, Mexico, J. Geophys. Res. 107 (2002), doi:10.1029/ 2000JB000099.

[26] P. Vanicek, E. Krakiwsky, Geodesy: The Concept, North-Holland, 1986.

[27] N.A.C. Cressie, Statistics for Spatial Data, Revised ed. John Wiley \& Sons, Inc., 1993.

[28] T. Arnadottir, P. Segall, The 1989 Loma Prieta earthquake imaged from inversion of geodetic data, J. Geophys. Res. 99 (1994) 21,835-21,846.

[29] B.J. Meade, B.H. Hager, S.C. McClusky, R.E. Reilinger, S. Ergintav, O. Lenk, A. Barka, H. Özener, Estimates of Seismic Potential in the Marmara Sea Region from Block Models of Secular Deformation Constrained by Global Positioning System Measurements, Bull. Seismol. Soc. Am. 92 (2002) 208-215.

[30] T. Rockwell, A. Barka, T. Dawson, K. Thorup, S. Akyuz, Paleoseismology of the Gazikoy-Saros segment of the North Anatolia fault, northwestern Turkey: Comparison of the historical and paleoseismic records, implications of regional seismic hazard, and models of earthquake recurrence, Int. J. Seismol. (2001) 433-448.

[31] R. Bürgmann, M.A. Ayhan, E.J. Fielding, T. Wright, S. McClusky, B. Aktug, C. Demir, O. Lenk, A. Trkezer, Deformation during the 12 November 1999, Düzce, Turkey Earthquake, from GPS and InSAR Data, Bull. Seismol. Soc. Am. 92 (2002) $161-171$.

[32] R.E. Reilinger, S. Ergintav, R. Bürgmann, S. McClusky, O. Lenk, A. Barka, O. Gurkan, L. Hearn, K.L. Feigl, R. Cakmak, B. Aktug, H. Ozener, M.N. Töksoz, Coseismic and postseismic fault slip for the 17 August 1999, $M=7.5$, Izmit, Turkey Earthquake, Science 289 (2000) 1519-1524.

[33] T. Parsons, Recalculated probability of $M \geq 7$ earthquakes beneath the Sea of Marmara, Turkey, J. Geophys. Res. 109 (2004) B05304, doi:10.1029/2003JB002667.

[34] C. Gurbuz, M. Aktar, H. Eyidogan, A. Cisternas, H. Haessler, A. Barka, M. Ergin, N. Turkelli, O. Polat, S.B. Ucer, S. Kuleli, S. Baris, B. Kaypak, T. Bekler, E. Zor, F. Bicmen, A. Yoruk, The seismotectonics of the Marmara region (Turkey): results from a microseismic experiment, Tectonophysics 316 (2000) 1-17.

[35] M.E. Ayhan, C. Demir, O. Lenk, A. Kilicoglu, Y. Altiner, A.A. Barka, S. Ergintav, H. Ozener, Interseismic strain accumulation in the Marmara Sea region, Bull. Seismol. Soc. Am. 92 (2002) 216-229.

[36] R. Armijo, B. Meyer, A. Hubert, A. Barka, Westward Propagation of the North Anatolian Fault into theNorthern Aegean: Timing and kinematics, Geology 27 (1999) 267-270.

[37] G.E. Hilley, R. Bürgmann, P. Molnar, P. Zhang, Bayesian inference of plastosphere viscosities near the Kunlun Fault, northern Tibet, Geophys. Res. Lett. 32 (2005), doi:10.1029/2004GL021658.

[38] K.M. Johnson, P. Segall, Viscoelastic cycle models of deep stress driven creep along the San Andreas Fault, J. Geophys. Res. 109 (2004), doi:10.1029/2004JB003096.

[39] K.M. Johnson, P. Segall, A viscoelastic earthquake cycle model for Taiwan, J. Geophys. Res. 110 (2005)

[40] E.H. Hearn, R. Bürgmann, R. Reilinger, Dynamics of Izmit Earthquake Postseismic Deformation and Loading of the Duzce Earthquake Hypocenter, Bull. Seismol. Soc. Am. 92 (2002) 172-193.

[41] A.M. Freed, R. Bürgmann, Evidence of powerlaw flow in the Mojave desert mantle, Nature 430 (2004) 548-551.

[42] S. Kenner, P. Segall, Lower crustal structure in Northern California: Implications from strain-sate variations following the 1906 San Francisco earthquake, J. Geophys. Res. 108 (2003), doi:10.1029/2001JB000189.

[43] W. Thatcher, Strain accumulation and release mechanism of the 1906 San Francisco earthquake, J. Geophys. Res. 80 (1975) 4862-4872.

[44] F.F. Pollitz, Transient rheology of the upper mantle beneath central Alaska inferred from the crustal velocity field following the 2002 Denali earthquake, J. Geophys. Res. 110 (2005).

[45] F.F. Pollitz, Transient rheology of the uppermost mantle beneath the Mojave Desert, California, Earth Planet. Sci. Lett. 215 (2003) 89-104.

[46] F.F. Pollitz, Mantle flow beneath a continental strike-slip fault: postseismic deformation after the 1999 Hector mine earthquake, Science 293 (2001) 1814-1818.

[47] S. Jónsson, P. Segall, R. Pedersen, G. Björnsson, Post-earthquake ground movements correlated to pore-pressure transients, Nature 424 (2003) 179-183.

[48] Y. Fialko, Evidence of fluid-filled upper crust from observations of post-seismic deformation due to the 1992 Mw7.3 Landers earthquake, J. Geophys Res. 109 (2004), doi:10.1029/2003JB002985. 